\title{
A IMPLEMENTAÇÃO DE POLÍTICAS PÚBLICAS DE LAZER E SUAS RELAÇÕES COM O CAPITAL CULTURAL DOS GESTORES MUNICIPAIS
}

Recebido em: 28/07/2016

Aceito em: 19/01/2017

\author{
Pedro Henrique Iglesiaz Menegaldo \\ Andréia Paula Basei \\ Eduard Angelo Bendrath \\ Universidade Estadual de Maringá \\ Ivaiporã - PR - Brasil
}

Campus Regional do Vale do Ivaí (UEM/CRV)

RESUMO: Este estudo discute as relações no que concerne ao capital cultural dos gestores das secretarias/departamentos de esporte e lazer e a implementação de políticas públicas em nove municípios localizados na microrregião geográfica de Ivaiporã, Paraná. Para tanto, realizou-se uma entrevista semiestruturada com os gestores dos municípios pesquisados, as quais foram analisadas com base no método de análise de conteúdo. Evidenciou-se um baixo acúmulo de capital cultural pelos gestores, os quais possuem um conhecimento restrito da área que reflete na implementação de políticas públicas municipais. Aponta-se a necessidade de os gestores ampliarem seu capital cultural relacionado a área do lazer, se apropriando dos conhecimentos da área, especificamente no que se refere ao planejamento, implantação, execução e controle de políticas públicas com vistas a atender as diferentes demandas sociais.

PALAVRAS CHAVE: Políticas Públicas. Atividades de Lazer.

\section{THE IMPLEMENTATION OF PUBLIC LEISURE POLICIES AND THEIR RELATIONSHIP WITH THE CULTURAL CAPITAL OF MUNICIPAL MANAGERS}

ABSTRACT: This study discusses the relationship regarding the cultural capital of the managers of departments / sports and leisure departments and the implementation of public policies in nine municipalities in the geographic micro-Ivaiporã, Paraná. Therefore, we carried out a semi-structured interview with the managers of the municipalities surveyed, which were analyzed based on the content analysis method. It was evidenced a low accumulation of cultural capital by managers, which have a limited knowledge of the area which reflects the implementation of municipal policies. It points to the need for managers to broaden their cultural capital related to leisure area, appropriating knowledge of the area, specifically with regard to planning, implementation, execution and control of public policies in order to meet the different social demands.

KEYWORDS: Public Policies. Leisure Activities 
Pedro Henrique I. Menegaldo, Andréia Paula Basei e A Implementação de Políticas Públicas de Lazer... Eduard Angelo Bendrath

\section{Introdução}

Atualmente no Brasil, é observável o crescimento de estudos abordando o tema lazer, com pesquisas em diversas áreas do conhecimento, tais como Terapia Ocupacional, Administração, Turismo, Fisioterapia, Economia, Psicologia, Arquitetura e Urbanismo, Educação Física, entre outras. No entanto, somente a partir da década de 1970, o lazer passou a concentrar e a propelir projetos, pesquisas e ações multidisciplinares, momento este em que se revela como a gênese da sistematização no campo de estudos do lazer e de intervenções que passaram a unir muitas iniciativas que anteriormente eram desenvolvidas de maneiras isoladas (GOMES; MELO, 2003).

Conforme Souza e Isayama (2006) apoiados em Sant'anna ${ }^{1}$ (1994) foi neste período que começam a surgir os livros, artigos científicos, teses e dissertações, da mesma forma que se expandem os relatórios de métodos empregados e dos resultados de programas de lazer que, até o momento eram homogêneos e desprovidos de contradições, porém transmitiam uma série de problemas e desigualdades sociais.

Neste percurso do desenvolvimento do campo de estudos do lazer, vários autores passaram a aprofundar os conhecimentos acerca desta temática, conduzidos por reflexões sociológicas até 1990 no Brasil. Posteriormente à este período, os estudos adotaram diversas perspectivas, ou seja, ao mesmo tempo que aumentava a produção de conhecimento na área, ampliavam-se os enfoques, as abordagens do lazer e os embates teóricos no campo (GOMES; MELO, 2003).

Neste período, mais exatamente em 1998, é criado no Brasil um periódico científico específico do lazer, a Revista LICERE, do Programa Interdisciplinar de Mestrado em Lazer, da Universidade Federal de Minas Gerais, que tem por objetivo

\footnotetext{
${ }^{1}$ SANT’ANNA, Denise B. O prazer justificado: História e lazer - (São Paulo, 1969/1979). São Paulo: Marco Zero/MCT-CNPq, 1994.
} 
Pedro Henrique I. Menegaldo, Andréia Paula Basei e A Implementação de Políticas Públicas de Lazer... Eduard Angelo Bendrath

colaborar com o desenvolvimento qualitativo dos estudos e experiências executadas, além de difundir e partilhar publicamente o conhecimento produzido (STOPPA et al., 2013). Atualmente, outros periódicos em nosso país, também publicam estudos que abordam diversas temáticas envolvendo o lazer - a Revista Brasileira de Estudos do Lazer, Motrivivência: Revista de Educação Física, Esporte e Lazer, Revista Movimento, Revista Brasileira de Ciências do Esporte, Revista Brasileira de Educação Física e Esporte, Revista Pensar a Prática - seja na área relacionada à Educação Física e Esporte, como os acima citados, seja em outras áreas do conhecimento que abordam o lazer com diferentes perspectivas.

Apesar do evidente crescimento na produção do conhecimento acerca do lazer, Tavares et al. (2009) relatam que a temática sobre a gestão do lazer, ainda carece de trabalhos direcionados as informações e conhecimentos sobre este campo de estudos. Neste sentido, este artigo aborda especificamente o campo da gestão pública do lazer, tendo por objetivo discutir as relações no que concerne ao capital cultural dos gestores das secretarias/departamentos de esporte e lazer e a implementação de políticas públicas em nove municípios localizados na microrregião geográfica de Ivaiporã, Paraná.

Deste modo, este estudo trata de uma pesquisa qualitativa de caráter descritivo. Os participantes foram os agentes públicos municipais, sendo estes os secretários, diretores e/ou chefes de divisão das Secretarias/Departamentos de Esporte e Lazer dos municípios selecionados.

A microrregião de Ivaiporã, PR é composta por 15 municípios e está localizada na Mesorregião Geográfica Norte Central Paranaense, possuindo uma área territorial de $6.161,014 \mathrm{~km}^{2}$ e uma população de aproximadamente 137.442 habitantes, sendo que 
Pedro Henrique I. Menegaldo, Andréia Paula Basei e A Implementação de Políticas Públicas de Lazer... Eduard Angelo Bendrath

$60 \%$ habitam a zona urbana ${ }^{2}$. Os municípios são de pequeno porte I e II (IBGE, 2010), no qual alguns apresentam elevados índices de pobreza, distintos níveis educacionais (poucos possuem significativa presença de estabelecimentos de Ensino Superior), e, a estrutura setorial de ocupação é caracterizada por serviços em indústria e comércio, e principalmente pela agropecuária (IPARDES, 2004).

Para a pesquisa foram selecionados apenas os municípios que possuíam acima de 5.000 habitantes $(n=10)$. Dentre estes, em um município não foi possível realizar a coleta de dados, pois o gestor alegou indisponibilidade no período destinado a esta etapa da pesquisa. Desta forma, os municípios participantes da pesquisa foram: Cândido de Abreu, Grandes Rios, Ivaiporã, Lunardelli, Manoel Ribas, Nova Tebas, Rosário do Ivaí, São João do Ivaí e São Pedro do Ivaí.

Com o intuito de analisar e discutir sobre o capital cultural acerca do lazer e a implementação de políticas públicas neste setor na gestão pública municipal, foi realizada uma entrevista semiestruturada com os gestores públicos dos nove municípios supracitados.

Importante ressaltar que para a realização da entrevista este trabalho foi aprovado pelo comitê de ética em pesquisa da Universidade Estadual de Maringá, estando de acordo com a Resolução 196/96 do Conselho Nacional de Saúde que trata do Código de Ética para Pesquisa em Seres Humanos, e os entrevistados assinaram o Termo de Consentimento Livre e Esclarecido (TCLE) para participar da pesquisa.

Todas as entrevistas foram gravadas e transcritas integralmente para posteriormente serem categorizadas e analisadas. $\mathrm{Na}$ análise dos dados foi utilizado o método da Análise de Conteúdo, que segundo Bardin (1977, p. 38) corresponde ao "[...]

\footnotetext{
2 Informações obtidas no site do Instituto Paranaense de Desenvolvimento Econômico e Social IPARDES. Disponível em: <http://www.ipardes.gov.br>.
} 
Pedro Henrique I. Menegaldo, Andréia Paula Basei e A Implementação de Políticas Públicas de Lazer... Eduard Angelo Bendrath

conjunto de técnicas de análise das comunicações, que utiliza procedimentos sistemáticos e objectivos de descrição do conteúdo das mensagens".

Os dados obtidos na pesquisa foram analisados com base na Teoria dos Campos de Pierre Bourdieu, na relação de campo, habitus, capital e capital cultural, estabelecendo relações com estudos da área do lazer e de políticas públicas.

\section{O Capital Cultural dos Gestores: Análise sobre a Apropriação e Acúmulo acerca} do Lazer

Antes de entrarmos nas especificidades da análise dos dados que emergiram da pesquisa empírica com os gestores, consideramos relevante expor as bases teóricas que esta análise será sustentada, isto é, compreender os conceitos de capital e capital cultural, bem como as diferentes formas deste capital conforme exposto por Bourdieu em diferentes obras que abordaram a temática (BOURDIEU, 1998 e 2013b; BOURDIEU; PASSERON, 2013; NOGUEIRA; CATANI, 2013; PRAXEDES, 2015). Estas reflexões serão pautadas na necessidade de analisar criticamente os conceitos e como se dá apropriação desta forma de capital pelos agentes tidos como foco deste estudo, sejam eles, os gestores de esporte e lazer dos municípios.

Bourdieu (2004a) relata que os agentes são importantes e fundamentais na concretização das ações em determinado campo (ou subcampo), sendo que este último só existe a partir das relações objetivas dos agentes que nele estão presentes. Para mais, ao se referir aos agentes explica que estes são caracterizados pelo volume de seu capital (acúmulo de conhecimentos, bens materiais ou simbólicos) que definem a estrutura do campo de acordo com seu peso e também depende do peso dos demais agentes, ou seja, de todo o espaço. 
Pedro Henrique I. Menegaldo, Andréia Paula Basei e A Implementação de Políticas Públicas de Lazer... Eduard Angelo Bendrath

Neste sentido, o conceito de capital pode ser entendido como o conjunto de recursos atuais ou potenciais dos agentes que podem assumir formas distintas (MEZZADRI; SILVA; FIGUEIRÔA, 2015). De acordo com Bourdieu (2004b), estas formas podem ser o capital econômico, cultural, social, simbólico, dentre outros.

Deste modo, o capital econômico refere-se à capacidade de apropriação material dos instrumentos de produção material e cultural, ou seja, aqueles que detêm a propriedade privada e os meios de produção (BOURDIEU, 2008).

Conforme Bourdieu, o capital social refere-se ao:

[...] o conjunto de recursos atuais ou potenciais que estão ligados à posse de uma rede durável de relações mais ou menos institucionalizadas de interconhecimento e de inter-reconhecimento ou, em outros termos, à vinculação a um grupo, como conjunto de agentes que não somente são dotados de propriedades comuns (passíveis de serem percebidas pelo observador, pelos outros ou por eles mesmos), mas também são unidos por ligações permanentes e úteis (NOGUEIRA; PASSERON, 2013, p. 67).

Portanto, o capital social de determinado agente depende diretamente da amplitude da rede de relações que o mesmo pode envolver e do volume de capital - seja econômico, cultural ou simbólico - dos membros aos quais está ligado (NOGUEIRA; CATANI, 2013).

Já o capital simbólico corresponde a um capital de qualquer espécie, que é percebido por um agente dotado de categorias de percepção derivados da apropriação da estrutura de sua distribuição, no qual é conhecido e reconhecido como algo incontestável, diz respeito ao reconhecimento da legitimidade, em que o mundo comum é apreendido como sendo uma coisa clara, natural, em consequência da causalidade entre as estruturas objetivas e das estruturas incorporadas (BOURDIEU, 2009).

O capital cultural é uma expressão cunhada e utilizada por Bourdieu para analisar situações de classe na sociedade. Portanto, nosso olhar estará voltado para o 
Pedro Henrique I. Menegaldo, Andréia Paula Basei e A Implementação de Políticas Públicas de Lazer... Eduard Angelo Bendrath

denominado capital cultural, o qual é definido na obra de Bourdieu de forma bastante abrangente e ambígua, servindo para indicar todas as maneiras que a cultura reflete ou atua sobre as condições de vida dos indivíduos, sendo,

[...] o conjunto de bens culturais que são transmitidos pela diferentes ações e cujo valor enquanto capital cultural é função da distância entre o arbitrário cultural imposto pela ação dominante e o arbitrário cultural inculcado pela ação nos diferentes grupos ou classes (BOURDIEU, 2013, p. 43).

Com base neste conceito, é possível compreendermos que, o capital cultural pode servir para caracterizar subculturas de classe ou de setores de classe. Voltando o olhar para o tema deste estudo, este conceito apresenta a possibilidade de caracterizar a subcultura dos gestores públicos de lazer, ou seja, o conhecimento acumulado por estes agentes, seu talento, sua criatividade, suas formas de compreensão e ação diante da necessidade de políticas públicas nos municípios.

Vale ressaltar que para Bourdieu (2013a, p. 208),

A cultura não é apenas um código comum nem mesmo um repertório comum de respostas a problemas recorrentes. Ela constitui um conjunto comum de esquemas fundamentais, previamente assimilados, e a partir dos quais se articula, segundo uma "arte da invenção" análoga à da escrita musical, uma infinidade de esquemas particulares diretamente aplicados a situações particulares.

Ressaltando a importância da transmissão do capital cultural, Bourdieu desenvolve sua argumentação apontando que este pode existir de três formas:

[...] no estado incorporado, ou seja, sob a forma de disposições duráveis do organismo; no estado objetivado, sob a forma de bens culturais - quadros, livros, dicionários, instrumentos, máquinas, que constituem indícios ou a realização de teorias ou de críticas dessas teorias, de problemáticas, etc.; e, enfim, no estado institucionalizado, forma de objetivação que é preciso colocar a parte porque, como se observa em relação ao certificado escolar, ela confere ao capital cultural - de que é, supostamente a garantia - propriedades inteiramente originais (NOGUEIRA; CATANI, 2013, p. 82, grifo dos autores). 
Pedro Henrique I. Menegaldo, Andréia Paula Basei e A Implementação de Políticas Públicas de Lazer... Eduard Angelo Bendrath

Para compreendermos a apropriação e o acúmulo do capital cultural e suas diferentes formas pelos gestores, elencamos questões relevantes por meio das quais podemos impulsionar nossas análises. A primeira delas é concernente à concepção de lazer destes agentes públicos, para analisar este aspecto, partindo do entendimento de que o lazer na sociedade contemporânea comporta vários entendimentos, em razão da recente incorporação do termo ao vocabulário comum (MARCELLINO, 2002). Portanto, compreender as concepções acerca do lazer, pelos gestores públicos municipais é fundamental, enquanto parâmetro para compreender as políticas públicas municipais neste setor, se coloca como forma de explicitar o capital cultural no seu estado incorporado no que se refere a área foco deste estudo.

Assim a concepção mais representativa sobre o lazer, apresentada está associada ao conteúdo físico e esportivo:

Eu interligo sempre o esporte e o lazer meio que em conjunto, uma coisa com a outra, embora sejam coisas diferentes (Gestor 2).

O lazer é o divertimento, tanto o cara participando como o jogador naquele momento né, como participante, como também passivo na arquibancada com a família distraindo [...] (Gestor 3).

O que eu posso te dizer o lazer aí é o final de semana desse pessoal que... nosso aí que [...] é praticamente só jogam bola e fazem atividades físicas. Aqui no município como é pequeno [...] o lazer deles é através de jogar bola nos finais de semana, caminhadas que a gente arrumou umas quadras e o campo pra caminhada, o lazer deles seria isso aí (Gestor 5).

É aquilo, é que a hora que a gente fala do esporte, que nem assim as pessoas mais velhas, eles vem mais pra cá como lazer né, eles num vem... acima de trinta assim, eles já vem brincar aqui pra poder ter o seu horário de lazer (Gestor 6).

$\mathrm{Na}$ fala do gestor 2 podemos verificar que o agente público admite que o esporte e o lazer são diferentes, assim como o gestor 1, contudo, ambos não conseguem conceituar o lazer e utilizam o esporte para exemplificar seu entendimento, 
Pedro Henrique I. Menegaldo, Andréia Paula Basei e A Implementação de Políticas Públicas de Lazer... Eduard Angelo Bendrath

direcionando sua fala a partir do panorama de atividades realizadas pelos cidadãos de seu município:

O lazer é um campo diferente do esporte, [...] aqui no nosso município e eu sou convicto a falar que a única fonte de lazer e a gente tá procurando melhorar isso, é o esporte [...] veja bem no nosso município foi instalado uma academia ao ar livre, que não é lazer, mas que para muitos não deixa de ser, aí no final da tarde e se encontram, eu entendo que para algumas pessoas é um lazer, foi instalado agora final do ano passado, então nós estamos muito atrasado no aspecto estrutural para dar uma condição de lazer para o nosso público e também é uma grande preocupação... e aqui principalmente na nossa comunidade do interior aos finais de semana, sábado, domingo, o lazer deles é jogar um truco na casa do compadre ou ir em campinho de futebol praticar um futebol, as menina ficam do lado jogando um vôlei, uma peteca... então esse é o lazer e aqui dentro da cidade a gente está tentando é impor alguns aspectos que possam melhorar o lazer da comunidade (Gestor 1).

Conforme Castellani Filho (2013, p. 13) “o esporte e o lazer constituem-se em conceitos distintos, nos quais o último não pode ser reduzido às fronteiras do primeiro”. O autor relata que esta relação entre esporte e lazer, no que tange a manifestação do esporte de participação, há a necessidade de incorporar uma política específica, ou seja, agregar uma política de lazer que não desenvolva apenas os interesses físico-esportivos. Aponta que estas políticas precisam contemplar uma série de interesses presentes em nosso quadro cultural.

Deste modo, o entendimento apresentado pelos gestores, quanto à utilização do termo lazer, segue a mesma direção apontada por Marcellino (2002, p. 7),

Com relação à utilização da palavra "lazer" o que se verifica, com maior frequência, é a simples associação com experiências individuais vivenciadas dentro de contexto mais abrangente que caracteriza a sociedade de consumo, o que, muitas vezes, implica a redução do conceito a visões parciais, restritas aos conteúdos de determinadas atividades.

Esta simples associação e restrição aos conteúdos das atividades, verificados nos gestores de esporte e lazer, principalmente do entendimento do lazer sobre a ótica do 
Pedro Henrique I. Menegaldo, Andréia Paula Basei e A Implementação de Políticas Públicas de Lazer... Eduard Angelo Bendrath

campo esportivo, trata-se de um processo de construção histórica que constitui tal relação de submissão do lazer ao universo esportivo, principalmente em situações anteriores e momentos no qual o esporte surge como produto da indústria cultural do entretenimento (CASTELLANI FILHO, 2013).

Esta visão restrita aos conteúdos das atividades, principalmente esportivas, pode ser verificada no entendimento apresentado pelo gestor 4:

Eu consideraria é todas as competições que a gente realiza, porque agora mesmo a gente tá com um campeonato municipal de futebol e nós temos essa competição [...] é para com os atletas certo [...]. Mas eu considero como lazer, porque você volta, você olha envolta do campo, você tem a comunidade local das faixas etárias, de todas as idades, é crianças, é adolescentes, pessoas já da terceira idade, então eu considero o seguinte, eu proporciono uma competição e ao mesmo tempo se torna um lazer pra comunidade toda, porque como nós, como já disse nós somos um município pequeno e quase não tem o que se desfrutar no final de semana e eu coloco nas minhas competições, como também competitivo para os atletas, formação para os nossos atletas e o lazer para a comunidade (Gestor 4).

As circunstâncias em que estão submetidas às atividades de lazer devem ser tomadas em consideração para que sejam caracterizadas, ou seja, algumas atividades podem ser extremamente prazerosas e atraentes para alguns indivíduos, enquanto para outros podem ocasionar desconforto e tédio (MARCELLINO, 2002).

Sobre estas circunstâncias das atividades, Marcellino (2002,p. 8) menciona que,

Se para algumas pessoas o futebol, a pescaria, a jardinagem constituem atividades de lazer, certamente isso não se verifica, em todas as oportunidades, para o jogador profissional, o pescador que depende da sua produção, ou para o jardineiro.

Neste sentido o autor aponta que o entendimento do lazer não pode se restringir apenas ao conteúdo da ação, não sendo atributo suficiente para sua conceituação. Para mais, aponta os aspectos fundamentais nas circunstâncias das atividades de lazer: o tempo, relacionado ao "tempo livre" ou liberado das atividades de trabalho, das 
Pedro Henrique I. Menegaldo, Andréia Paula Basei e A Implementação de Políticas Públicas de Lazer... Eduard Angelo Bendrath

obrigações familiares, religiosas e sociais; e, a atitude, compreendida como a relação entre o sujeito e a experiência vivida, portanto a satisfação incitada pela atividade.

Partindo destes aspectos, em relação ao tempo e atitude, identificamos nas falas dos gestores 3 e 8 , a concepção funcionalista do lazer, relacionada as compensações e reestabelecimento das forças do trabalho

[...] o lazer é muito importante nós temos que ter, por que temos os cidadãos que trabalha aí mensal, ele tem que pegar um sábado e domingo ter um lazer, lazer musical, lazer de esporte, lazer cultural, isso é fundamental num processo também (Gestor 3).

$[\ldots]$ nós temos que ter um período de lazer nosso [...] então quer dizer tem treinamento é falo muito do profissional, porque você tem o trabalho se dedicar, se apegar, que você tem que da o seu máximo, só que você tem o momento de lazer que é aquilo ali que você vai buscar a energia sua e resgatar aquela força, recarregar as bateria pra você ter força [...] quer dizer o lazer com seu filho, lazer com sua esposa, lazer com seus amigos né (Gestor 8).

Deste modo, identificamos a partir destes entendimentos a abordagem compensatória do lazer, ou seja, caracterizada pela compensação da insatisfação e alienação do trabalho, e, também a abordagem utilitarista, através da perspectiva reducionista do lazer, tendo como finalidade a recuperação da força de trabalho e como instrumento de desenvolvimento. Sendo assim, o lazer através da abordagem funcionalista é compreendido como um fator de ajuda, que busca a paz social e a manutenção da ordem (MARCELLINO, 1987, p. 38).

A partir do exposto, identificou-se de maneira geral que os gestores não conseguem conceituar e/ou apresentar claramente seu entendimento sobre o lazer. Neste sentido, os gestores 2 e 7 admitem em suas falas o desconhecimento e falta de argumentos suficientes para expor seu entendimento sobre o lazer:

O lazer, então o lazer não sei muito te responder, como daria parte do lazer (Gestor 2).

Eu falo pra vocês, não sei se eu to certo [risos] (Gestor 7). 
Pedro Henrique I. Menegaldo, Andréia Paula Basei e A Implementação de Políticas Públicas de Lazer... Eduard Angelo Bendrath

Apesar de estes gestores terem apresentado suas concepções sobre o lazer, tais agentes, mesmo que timidamente, admitem desconhecimento e insegurança sobre o conteúdo. A ausência deste capital cultural pode ser em razão da falta de formação em Educação Física - área que se apropriou dos estudos e ações no campo do lazer - ou mesmo pela formação precária ou deficitária nas instituições de ensino.

O gestor 9, por sua vez, apresenta uma concepção de lazer abrangente

O lazer pra mim [...] eu [...] ela tem que ser assim aberta a todas as pessoas né, dependendo do grau de formação ou quem quer que seja desde da criança né, o adolescente, as pessoas idosas [...] tenha um lugar apropriado com pessoas qualificadas pra né pra tá sempre fazendo acompanhamento (Gestor 9).

Na perspectiva política seu entendimento parte da concepção de lazer enquanto direito dos cidadãos e com espaços, equipamentos e profissionais especializados na área. Entretanto, é necessário rever a questão sobre a qualificação do profissional na área do lazer, quanto à capacidade de articulação das ações de forma a atender as necessidades da população neste setor.

Neste sentido, o tema sobre a formação no exercício da atividade profissional na área do lazer, vem adquirindo espaço no cenário nacional, motivados pela expansão das demandas de mercado. Entretanto, tal formação visa proporcionar uma capacitação, a partir de uma perspectiva abstrata de lazer aos denominados especialistas tradicionais. Deste modo, o mercado rege o tipo de profissional a ser formado, sob a perspectiva do esporte e o lazer enquanto mercadorias a serem consumidas no tempo disponível, até mesmo como forma de controle social (MARCELLINO et al., 2007a). Tal perspectiva no âmbito público não garante o direito dos cidadãos sobre os conteúdos do lazer e ainda pode ser uma ferramenta utilizada como forma de manipulação político ideológico da população. 
Pedro Henrique I. Menegaldo, Andréia Paula Basei e A Implementação de Políticas Públicas de Lazer... Eduard Angelo Bendrath

Nesta perspectiva, a discussão sobre o lazer vinculado a elaboração de políticas de atuação, deve-se considerar primeiramente a abrangência do lazer e tomar como consideração seu entendimento parcial e limitado, evidenciados nas pesquisas, nas ações dos órgãos públicos, na legislação, entre outros (MARCELLINO et al., 2007b).

Este entendimento limitado e parcial do lazer e também restrito a um de seus conteúdos - o conteúdo físico e esportivo para este grupo de agentes - pode ter relação com própria definição do campo, que não fica evidenciada nas instituições públicas, segundo Marcellino et al. (2007b, p. 14):

\begin{abstract}
Nem mesmo na denominação de órgãos públicos a definição do campo abrangido pelo lazer fica evidenciada. A partir da década de setenta, incorporou-se o tema para denominar repartições de prestação de serviços públicos, geralmente associando-o, restritivamente, a setores culturais específicos. Não são poucas, nos âmbitos, estadual e principalmente municipal, as Secretarias e Divisões de "Esportes e Lazer", "Recreação e Lazer", "Cultura e Lazer", "Turismo e Lazer", etc.
\end{abstract}

Nas prefeituras pesquisadas, o lazer nas secretarias e departamentos está vinculado principalmente com o Esporte, em alguns casos em conjunto com o Turismo e Educação. Conforme Marcellino et al. (2007b), este entendimento prejudica a implantação de ações específicas e dificulta identificação dos valores associados ao lazer, prendendo-se ao entendimento do senso comum associado ao divertimento e ao descanso, em detrimento do desenvolvimento social e pessoal, que podem ser fornecidos pelo lazer.

Com base nas informações empíricas, na discussão teórica e na compreensão de que, o capital cultural são as habilidades e as competências que os gestores adquirem ao longo de suas vidas, as quais podem ser uma mistura da cultura dominante ou o habitus que os gestores adquirem em seu convívio social, é possível compreendermos a concepção reducionista do lazer apresentada por eles, logo a limitação no acúmulo do 
capital cultural enquanto aquele que indica acesso a conhecimento e informações ligadas a uma cultura específica, neste caso o lazer e suas múltiplas dimensões e conteúdos. A importância de analisar estas questões reside no fato de que elas poderão sustentar o entendimento a respeito das ações promovidas ou das limitações com relação as mesmas.

Em se tratando especificamente dos diferentes estados do capital cultural tratados por Bourdieu, evidencia-se que, o acúmulo do capital cultural no estado incorporado (BOURDIEU, 2013b) pelos gestores é bastante deficitário, uma vez que, sua construção demanda tempo e investimento pessoal, para que o indivíduo vá se apropriando de maneira singular no convívio e socialização com diferentes atores, neste caso, outros gestores, estudiosos, pesquisadores, pessoas ligadas à área e mesmo com a população em geral. Mesmo encontrando esta limitação, conhecer estes aspectos ganha importância quando necessário pensar em formas de ampliar o capital cultural dos gestores, ou seja, o que ele carrega consigo deve ser considerado para começar a atuar e planejar ações com vistas a melhoria na qualidade das ações desenvolvidas por eles e ao atendimento das demandas sociais.

Importante mencionar também as limitações quanto ao acúmulo deste capital no seu estado institucionalizado, uma vez que, não possuem formação específica na área acadêmica que poderia thes fornecer um suporte para exercer esta função, bem como não participam de cursos de formação, tanto na área da gestão ou outra correlata a função que desempenham. 
Pedro Henrique I. Menegaldo, Andréia Paula Basei e A Implementação de Políticas Públicas de Lazer... Eduard Angelo Bendrath

\section{Políticas Públicas de Lazer dos Municípios: Das Necessidades a Realidade das} Ações Promovidas

O lazer é parte constituinte da sociedade contemporânea, resultado das transformações no decorrer histórico das novas formas de produção (STIGGER, 2003), que no cenário nacional foi adquirindo espaço e passou a ser um direito social previsto no Art. $6^{\circ}$ da Constituição Federal (BRASIL, 1988), que deve ser assegurado pelo Estado, na qual os governos são responsáveis por articular e implantar políticas públicas que visem garantir o acesso do mesmo a todas as camadas da população.

Deste modo, em relação às políticas públicas de lazer na região pesquisada, o cenário é preocupante, pela escassez de ações voltadas para a garantia deste direito social e os equívocos conceituais apresentados pelos gestores. Deste modo, nos municípios de Cândido de Abreu, Grandes Rios, Ivaiporã, Lunardelli e Nova Tebas as ações baseiam-se em atividades esporádicas realizadas em datas festivas e em ocasiões específicas, em poucos casos verifica-se um programa de desenvolvimento contínuo:

Então projeto de lazer a gente tem [...] temos aí alguns eventos como atividades específicas, assim como o dia do índio, nós já sentamos com o cacique vamos fazer uma gincana lá, um dia de atividades pra eles [...] é como a gente tem um distrito aqui que se chama Tereza Cristina uma vez por semana com parceria com a promoção social outro departamento é vai estagiários de educação física fazer atividades recreativas com eles temos alguns eventos rotineiros que fazemos aqui no ginásio de esportes, exemplo o torneio de vôlei, torneio de tênis de mesa, essas ações voltadas conforme os interesse deles, às vezes fazemos um vôlei de areia, as vezes um [...] por exemplo dia 08 de março, dia da mulher já vamos fazer um evento dia da mulher, jogar vôlei qualquer coisa a gente pergunta ali faz uma pesquisa pra ver qual é o interesse delas e nos dois primeiro anos a gente já fez agora vamos fazer mais ou menos dessa forma (Gestor 1).

[...] a gente trabalha também é o lazer e recreação, que daí a gente tira uma vez por mês desce lá no campo e trabalha todas as brincadeiras que a gente não consegue ver mais agora a bets, a queimada, corrida de saco, elástico, a gente tira um dia assim só pra trabalha daí vai todas as crianças lá, por isso que daí eu trabalho junto com [...] em parceria com o CRAS, porque daí eles pega e levam, daí eles entram com a parte de alimentação pras crianças, alimentação, água, 'refri' é 
Pedro Henrique I. Menegaldo, Andréia Paula Basei e A Implementação de Políticas Públicas de Lazer... Eduard Angelo Bendrath

tudo que precisa nessa parte de alimentação eles levam e eu entro com a parte prática, assim das atividades (Gestor 6).

Por conseguinte, Maia (2003) menciona que, no poder público, os eventos tradicionais, os esporádicos, sem continuidade e sem participação popular na sua elaboração e planejamento, não são suficientes. Tais problemas estão relacionados aos equívocos no entendimento de políticas públicas, principalmente em relação às políticas setoriais de lazer, em que a primazia não se refere a sua situação setorial, mas associado ao seu isolamento, no qual o mesmo não é entendido na totalidade das relações sociais (MARCELLINO, 2001).

Desta forma, além de ações esporádicas, voltadas majoritariamente à recreação, outro fator alarmante é que, em praticamente todos os municípios há um forte direcionamento das ações ao conteúdo físico e esportivo. Entretanto, esta questão tornase ainda mais crítica, devido alguns gestores associar o treinamento e as competições esportivas como ações voltadas para o lazer:

Então, o lazer como eu disse pra você é as competições que a gente realiza, é nós temos é, como é que eu posso falar pra você, nós temos é trabalhos voltados para a juventude e a gente queria mais né [...] (Gestor 4).

Não, não, para o lazer não né. Eu a gente tenta fazer sempre isso né, a gente... fazer como se os nossos campeonatos se tornasse vamos dizer assim o lazer do pessoal sabe, e também a nossa melhoria, que nem a gente fez pista, a pista nossa de caminhada 'pro' pessoal ir em volta do campo, iluminamos a pista de caminhada (Gestor 5).

Treinamento, principalmente pra abrange mais escolaridade, eu faço três vez por semana, é, quando tem jogos participa (Gestor 7).

Neste sentido, além dos equívocos acerca do entendimento em que o treinamento é lazer e que as competições propiciam o lazer aos cidadãos, no qual podem em determinadas ocasiões proporcionar a determinado grupo, relacionado aos aspectos subjetivos dos sujeitos. Entretanto, evidencia-se o lazer passivo, no qual esses 
Pedro Henrique I. Menegaldo, Andréia Paula Basei e A Implementação de Políticas Públicas de Lazer... Eduard Angelo Bendrath

espectadores assumem o papel apenas de consumidores, não participando ativamente de ações que realmente o lazer proporcione o desenvolvimento humano e social, desconsiderando as necessidades da comunidade e não tornam as ações abrangentes.

Conforme Marcellino (2001), esta associação do lazer ao esporte tem relação com a Constituição Federal de 1988, pelo fato do documento estar carregado de vícios assistencialistas, que não é suficiente para dar conta do direito a felicidade, atribuindo ao lazer um caráter de utilidade, expõe também que a associação exclusiva a um conteúdo, no caso o esporte, ocasiona a redução da abrangência do lazer. Neste sentido, as políticas que os gestores consideram como de lazer não são abrangentes, pois ao considerar que as ações promovidas no esporte fornecem o lazer para a população, logo estas são focalizadas apenas há uma demanda da população diretamente envolvida nas modalidades esportivas e no consumo destas práticas.

Quanto a abrangência, Rechia et al. (2015, p. 228) aponta que é

[...] preciso que as políticas públicas voltadas ao lazer não sejam pensadas apenas para uma determinada parte da sociedade, ou com características restritas, mas para a sociedade no seu conjunto, garantindo a diversidade e a inclusão de todos.

Deste modo, em relação às políticas públicas de lazer, apenas os municípios de

Grandes Rios e Lunardelli, possuem programas e projetos do governo federal e estadual, sendo o Programa Segundo Tempo (PST) e Projeto Lazer no Paraná, respectivamente:

Tem, tem o [...] devia ter pego os papéis pra pode te informar melhor, sobre o Segundo Tempo que tem que é voltado 'pro' lazer e entre outros programas que a gente tem, até mesmo vinculado com secretaria de educação, onde que é mais voltado 'pro' lazer (Gestor 2).

Olha nós temos também é eu esqueci de colocar pra você, nós temos o projeto Lazer no Paraná, aonde a gente recebe materiais e a gente desenvolve também essas atividades né, é aonde que a gente tem, nós tivemos o Carlos (nome fictício) no ano passado que foi pra Curitiba, pra fazer um curso de capacitação e de lá a gente recebe materiais, é bolas a gente recebe materiais é pedagógicos, nós recebemos é redes 
Pedro Henrique I. Menegaldo, Andréia Paula Basei e A Implementação de Políticas Públicas de Lazer... Eduard Angelo Bendrath

né, então aí a gente [...] ajuda a gente a desenvolve esses trabalhos né, ajuda a gente fazer mais competições [...] (Gestor 4).

Deste modo, o PST trata-se de um programa voltado à democratização do acesso a prática e a cultura esportiva, tem como objetivo promover o desenvolvimento integral das crianças, jovens e adolescentes, em situação de vulnerabilidade social, proporcionando formação da cidadania e melhoria da qualidade de vida, por meio de práticas esportivas educativas, tendo como um de seus princípios o esporte e o lazer enquanto direito e dever do Estado ${ }^{3}$. Neste sentido, apesar do PST ser um programa destinado ao esporte-educação, abrange dentro de seus princípios o lazer, no qual o gestor o associou como uma ação voltada também para este setor.

Já o Projeto Lazer no Paraná tem por objetivo contemplar pequenos municípios, para que seus cidadãos tenham oportunidades de vivenciar momentos de entretenimento e descontração, por meio de atividades lúdicas ou pela prática esportiva. A Secretaria do Esporte do Paraná é responsável por realizar a capacitação dos gestores e fornecer kits de materiais, cabendo ao município contratar um estagiário para desenvolver as atividades junto à sua população ${ }^{4}$.

Apesar de serem programas diferentes, ambos apresentam um caráter voltado para o lazer, o esporte e a educação. Mas o que chama a atenção é a fala do gestor 4, que apresenta os benefícios propiciados pelo projeto ao qual foi contemplado, porém ao final relata que este auxilia a realizar mais competições. Neste sentido será que as diretrizes das ações por meio de tal projeto, garantem o acesso de práticas que oportunizam aos cidadãos o envolvimento com o lazer? Portanto, ao citar as competições, incorre-se o fato de que dependendo do direcionamento de suas ações,

\footnotetext{
${ }^{3}$ Informações obtidas no site do Ministério dos Esportes. Disponível em: <http://portal.Esporte.gov.br/ snee/segundotempo/default.jsp $>$. Acesso em: 13 jun. 2016.

4 Informações do site da Secretaria do Esporte e Turismo do Estado do Paraná. Disponível em: $<$ http://www.esporte.pr.gov.br/modules/noticias/article.php?storyid=4570>. Acesso em: 13 jun. 2016.
} 
Pedro Henrique I. Menegaldo, Andréia Paula Basei e A Implementação de Políticas Públicas de Lazer... Eduard Angelo Bendrath

podem não estar democratizando o acesso ao lazer e vinculando os benefícios do programa diretamente a prática esportiva competitiva.

A partir destas considerações, verifica-se de maneira geral que os gestores têm uma compreensão limitada acerca do lazer e as ações não contemplam o acesso a este direito, para os vários públicos de abrangência. Outro fato preocupante, diz respeito ao município de São João do Ivaí, no qual o gestor por não ter consolidado o planejamento de suas ações, menciona que os programas e projetos voltados para o lazer não estavam nos planos de ação de seu departamento até o momento. Portanto, podemos estabelecer que dentro das ações municipais o lazer é relegado a segundo plano ou até mesmo negligenciado, em relação à outras demandas sociais. Neste sentido, o lazer necessita estar na preocupação também das outras secretarias e departamentos, de forma a ser contemplado no planejamento das ações e na garantia deste direito.

Deste modo, partilhamos do pensamento de Reis e Starepravo (2008) de que o lazer se inter-relaciona com as demais esferas sociais, e as ações teriam de ser executadas em conjunto, em contrapartida a hierarquia de prioridades na gestão pública. Portanto, o segmento do lazer precisa da interação político-administrativa, na qual o governo deve compreender a importância da ação conjunta com outros segmentos públicos, como educação, cultura, habitação, ação social, planejamento urbano, entre outros (MAIA, 2003). De acordo com Marcellino (2001), tal ótica está pautada no entendimento amplo do lazer e sua interdisciplinaridade, corroborando a necessidade de trabalho integrado entre os diversos departamentos e secretarias da gestão pública municipal, ou seja, necessita que o poder público municipal institua políticas públicas intersetoriais, que considerem a representatividade da participação popular.

Falar numa política de lazer significa falar não só de uma política de atividades, que na maioria das vezes acabam por se constituir em 
eventos isolados, e não em política de animação como processo: significa falar em redução de jornada de trabalho - sem redução de salários, e, portanto, numa política de reordenação do tempo, numa política de transporte urbano etc.; significa, também, falar numa política de reordenação do solo - urbano, incluindo aí os espaços e equipamentos de lazer, o que inclui a moradia e seu entorno; e, finalmente, numa política de formação de quadros, profissionais e voluntários para trabalharem de forma eficiente e atualizada. Resumindo: o lazer tem sua especificidade, inclusive como política pública, mas não pode ser tratada de forma isolada de outras questões sociais (MARCELLINO, 2001, p 12).

$\mathrm{O}$ autor apresenta as questões a serem consideradas nas políticas de lazer, no qual integram diversos aspectos da vida social, como a relação com os espaços urbanos, recursos humanos, integração entre os diversos setores públicos, ou seja, o lazer possui suas especificidades que devem ser consideradas e pensadas estrategicamente na elaboração das políticas públicas.

Segundo Reis e Starepravo (2008) para que uma política pública de lazer se efetive, é necessário considerar três vias: a disponibilização dos espaços e equipamentos de lazer, tanto na manutenção e construção, quanto no investimento em aparatos para as diversas manifestações culturais e de lazer; a acessibilidade, relacionado com as possiblidades de acesso a estes espaços e equipamentos, considerando o transporte, a estruturação urbana e os custos financeiros; e a educação, referindo-se a formação dos indivíduos, para que vivencie as possibilidades do lazer e tenham conhecimento para estimular a procura e reivindicar este direito.

A partir do quadro apresentado sobre as políticas públicas de lazer da microrregião de Ivaiporã, PR, e, alicerçado nos pressupostos de Bourdieu a respeito da atuação dos agentes no campo social, os quais “[...] estão inseridos na estrutura e em posições que dependem do seu capital e desenvolvem estratégias que dependem, elas próprias, em grande parte, dessas posições, nos limites de suas disposições" (BOURDIEU, 2004a, p. 29), fica evidente que as estratégias na implantação das 
políticas públicas de lazer dos gestores estudados, dependem diretamente do limite de suas disposições, ou seja, do capital cultural específico do lazer. Esta carência de conhecimentos materializa-se na escassez de ações neste segmento da gestão pública municipal, que caminha no sentido da conservação da estrutura vigente, ao invés das transformações nas políticas a serem implantadas e desenvolvidas, que são incorporados ao habitus dos gestores, sendo entendido como conjunto de disposições que levam um agente ou classe de agentes as escolhas de bens e práticas (ORTIZ, 1983), que não garantem a democratização do acesso ao lazer.

\section{Considerações Finais}

Com base na perspectiva sociológica de Bourdieu, em especial nos conceitos de capital e capital cultural, procuramos fazer a análise das relações existentes entre a apropriação do capital cultural do lazer pelos gestores públicos e as políticas públicas municipais na área. Considerando que o capital cultural trata-se de um sistema de preferências correspondente às escolhas escolares e sociais, ou seja, aquele que indica acesso a conhecimento e informações ligadas a uma cultura específica; condicionado ao polo intelectual, dotados de opiniões e práticas correspondentes (BOURDIEU, 2008), o capital cultural dos gestores se apresenta como um importante instrumento para compreendermos as politicas públicas.

No entanto, torna-se evidente uma defasagem na apropriação destes conhecimentos pelos gestores municipais, já que, devido a inúmeros aspectos, dentre os quais destacamos as questões de formação profissional e do acúmulo do capital cultural, que indica todas as maneiras em que a cultura reflete ou atua sobre as condições de vida dos indivíduos, os gestores possuem um conhecimento bastante limitado, ou mesmo 
desconhecem inúmeras questões relativas aos estudos na área do lazer que vão desde a amplitude de sua conceituação até a diversidade de conteúdos que fazem parte do lazer

e que deveriam ser explorados no momento do planejamento e implementação de políticas públicas.

Este entendimento reducionista dos gestores sobre o lazer consubstancialmente torna as ações restritas, pois como os mesmos não conhecem todos os conteúdos ou até mesmo os que não têm conhecimento sobre o assunto, não possuem dimensão $\mathrm{e}$ amplitude das possibilidades, logo, não investem neste segmento como política pública.

Apontamos a necessidade de investimento em capital cultural, seja ele incorporado, objetivado ou institucionalizado, específico do lazer, já que, ele é relevante na atuação dos gestores para que possam ter conhecimentos das possibilidades de planejar e organizar as melhores estratégias de ação, implantar políticas públicas neste segmento, e para avançar na questão da interdisciplinaridade do lazer. Além disso, é determinante no controle da eficiência das políticas públicas no setor e da capacidade de promover o desenvolvimento humano e social.

\section{REFERÊNCIAS}

BARDIN, L. Análise de Conteúdo. Lisboa, Portugal: Edições 70, LTDA., 1977.

BOURDIEU, P. Sistemas de ensino e sistemas de pensamento. In: BOURDIEU, P. A economia das trocas simbólicas. 7. ed. São Paulo: Perspectiva, 2013a. pp. 203-229.

A economia das trocas simbólicas. 7. ed. São Paulo: Perspectiva, 2013 b.

Coisas ditas. São Paulo: Brasiliense, 2004b.

. O poder simbólico. Rio de Janeiro: Bertrand Brasil, 2009.

Os usos sociais da ciência: por uma sociologia clínica do campo científico. São Paulo: Ed. da Unesp, 2004a.

Razões práticas: sobre a teoria da ação. 9. ed. Campinas: Papirus, 2008. 
Pedro Henrique I. Menegaldo, Andréia Paula Basei e A Implementação de Políticas Públicas de Lazer... Eduard Angelo Bendrath

BOURDIEU, P.; PASSERON, J. C. A reprodução: elementos para uma teoria do sistema de ensino. 6.ed. Petrópolis: Vozes, 2013.

BRASIL. Constituição da República Federativa do Brasil de 1988, de 05 de outubro de 1988. Brasília, 1988.

CASTELLANI FILHO, L. Educação física, esporte e lazer: reflexões nada aleatórias. Campinas: Autores Associados, 2013.

GOMES, C. L.; MELO, V. A. Lazer no Brasil: trajetória de estudos, possibilidades de pesquisa. Revista Movimento, Porto Alegre, v. 9, n. 1, p. 23-44, jan./abr. 2003.

IBGE. Instituto Brasileiro de Geografia e Estatística. Pesquisa Nacional por Amostra de Domicílios. Síntese dos Indicadores de 2009. Rio de Janeiro: IBGE, 2010.

IPARDES. Instituto Paranaense de Desenvolvimento Econômico e Social. Leituras regionais: Mesorregião Geográfica Norte Central Paranaense. Curitiba: IPARDES: BRDE, 2004.

MAIA, L. F. S. A formação de técnico em lazer e suas possibilidades de atuação e intervenção em políticas públicas. In: MARCELLINO, N. C. Formação e desenvolvimento de pessoal em lazer e esporte: Para atuação em políticas públicas. Campinas: Papirus, 2003.p. $81-100$.

MARCELLINO, N. C. Estudos do lazer: uma introdução. 3. ed. Campinas: Autores Associados, 2002.

Lazer e Educação. Campinas: Papirus, 1987.

. Políticas de Lazer: Mercadores ou Educadores? Os cínicos bobos da corte. In: MARCELLINO, N. C. Lazer e esporte: políticas públicas. Campinas: Autores Associados, 2001.

. et al. Lazer, cultura e patrimônio ambiental urbano - políticas públicas: os casos de Campinas e Piracicaba, SP. Curitiba: OPUS, $2007 \mathrm{~b}$.

. et al. Políticas públicas de lazer: formação e desenvolvimento de pessoal: os casos de Campinas e Piracicaba, SP. Curitiba: OPUS, 2007a.

MEZZADRI, F. M.; SILVA, M. M.; FIGUERÔA, K. M. Desenvolvimento de um método para as pesquisas em políticas públicas de esporte no Brasil: uma abordagem de pesquisa mista. Revista Motrivivência, Florianópolis, v. 27, n. 44, p. 49-63, maio 2015.

NOGUEIRA, M. A.; CATANI, A. (Org.). Pierre Bourdieu - Escritos de educação. 14. ed. Petrópolis: Vozes, 2013.

ORTIZ, R. Pierre Bourdieu: sociologia. São Paulo: Ática, 1983. 
PRAXEDES, W. A educação reflexiva na teoria social de Pierre Bourdieu. São Paulo: Loyola, 2015.

RECHIA, S. et al. O lugar do lazer nas políticas públicas: um olhar sobre alguns cenários. Revista Licere, Belo Horizonte, v.18, n.1, p. 225-246, mar. 2015.

REIS, L. J. A.; STAREPRAVO, F. A. Políticas públicas para o lazer: pontos de vista de alguns teóricos do lazer no Brasil. Revista Licere, Belo Horizonte, v.11, n.2, p. 1 - 20 , ago. 2008.

SOUZA, A. P. T.; ISAYAMA, H. F. Lazer e educação física: análise dos grupos de pesquisa em lazer cadastrados na plataforma LATTES do CNPq. Revista Digital Efdeportes. Buenos Aires. Ano 11, n. 9. 2006.

STIGGER, M. P. Políticas públicas em esportes e lazer: considerações sobre o papel do profissional educador. In: MARCELLINO, N. C. Formação e desenvolvimento de pessoal em lazer e esporte: Para atuação em políticas públicas. Campinas: Papirus, 2003.

STOPPA, E. A. et al. A produção do conhecimento na área do lazer: uma análise sobre a Revista Licere-Atuação Profissional. Revista Pensar a Prática, Goiânia, v. 16, n. 3, p. 619 - 955, jul./set. 2013.

TAVARES, G. H. et al. Gestão do lazer: os grupos de pesquisa em foco. Revista Motriz, Rio Claro, v.15, n.3 p.470 - 480, jul./set. 2009.

\section{Endereço dos Autores:}

Pedro Henrique Iglesiaz Menegaldo

Rua Júlio Guerra, n 116 - Bairro Jardim Luiz XV

Ivaiporã - PR - 86.870-000

Endereço Eletrônico: pedromenegaldo@hotmail.com.br

Andréia Paula Basei

Universidade Estadual de Maringá, Campus Regional do Vale do Ivaí

Praça Independência, n. 385 - Centro

Ivaiporã - PR - 86.870-000

Endereço Eletrônico: andreiabasei@yahoo.com.br

Eduard Angelo Bendrath

Universidade Estadual de Maringá, Campus Regional do Vale do Ivaí

Praça Independência, n. 385 - Centro

Ivaiporã - PR - 86.870-000

Endereço Eletrônico: bendrath@gmail.com 